\title{
Wet snow hazard for power lines: a forecast and alert system applied in Italy
}

\author{
P. Bonelli, M. Lacavalla, P. Marcacci, G. Mariani, and G. Stella \\ RSE S.p.A. (former ERSE), Via Rubattino 54, 20134 Milano, Italy \\ Received: 16 July 2010 - Revised: 24 January 2011 - Accepted: 22 July 2011 - Published: 9 September 2011
}

\begin{abstract}
Wet snow icing accretion on power lines is a real problem in Italy, causing failures on high and medium voltage power supplies during the cold season. The phenomenon is a process in which many large and local scale variables contribute in a complex way and not completely understood. A numerical weather forecast can be used to select areas where wet snow accretion has an high probability of occurring, but a specific accretion model must also be used to estimate the load of an ice sleeve and its hazard. All the information must be carefully selected and shown to the electric grid operator in order to warn him promptly.

The authors describe a prototype of forecast and alert system, WOLF (Wet snow Overload aLert and Forecast), developed and applied in Italy. The prototype elaborates the output of a numerical weather prediction model, as temperature, precipitation, wind intensity and direction, to determine the areas of potential risk for the power lines. Then an accretion model computes the ice sleeves' load for different conductor diameters. The highest values are selected and displayed on a WEB-GIS application principally devoted to the electric operator, but also to more expert users. Some experimental field campaigns have been conducted to better parameterize the accretion model. Comparisons between real accidents and forecasted icing conditions are presented and discussed.
\end{abstract}

\section{Introduction}

Icing formation on structures and power lines is an important natural hazard that causes damage in many countries (Fikke, 2005a, b; Fikke et al., 2007; Cigrè, 2009). Two kinds of phenomena are involved: in-cloud icing, due to the supercooled water contained in the cold low-clouds, and precipitation icing, due to the freezing rain or the wet snow deposition

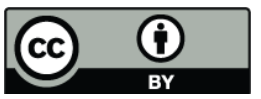

Correspondence to: P. Bonelli

(pbonelli@rse-web.it)
(Farzaneh, 2008; Poots, 1996). In Italy, as well as in other Mediterranean countries, especially at low altitude, the wet snow icing process is more important than the in-cloud one (Admirat and Sakamoto, 1988a, b; Bonelli and Lacavalla, 2010). In fact, snowfall precipitation, with temperatures close to $0^{\circ} \mathrm{C}$, is more frequent than humid and cold-cloud advections near the ground. At high altitude and in mountain regions, in-cloud icing may be important, but the power lines are rare and they are built with hardiness criteria (IEC, 1991; IEC, 1997; IEC, 2003).

The atmospheric icing process is an interesting subject for the electric grid design as well. In fact, as other severe weather phenomena, the icing frequency undergoes Global Climate Change and its long-term behaviour may be considered in building criteria. Atmospheric icing has been analysed from a climate point of view in Czech Republic, measuring ice-load deposition for a long time in the station of Studnice (Cigrè, 2005). The analysis shows a positive trend that is explained as a probable effect of Global Warming. In Italy as well, the frequency of "warm and wet" snowfall events, observed by means of SYNOP data since 1951, shows a positive trend (Bonelli and Lacavalla, 2010).

\subsection{Icing in Italy}

In the last years, northern regions of Italy suffered some severe snow events. In December 2008, heavy snowfall over the pre-alpine area, close to the city of Bergamo (Lombardy), at about $900 \mathrm{~m}$ a.s.l., caused the collapse of a lattice and many users were affected by days of electrical blackout. On the 15 December of the same year, another snow storm involved Piedmont, with more than $2 \mathrm{~m}$ of snow on the ground and the collapse of some overhead lines at about $800 \mathrm{~m}$ a.s.l. of altitude. This break caused the lack of power for 50000 habitants. On the 28 April 2009, in the Gressoney Valley (Valle d'Aosta) at an altitude of $1800 \mathrm{~m}$ a.s.l., a high voltage conductor broke down during a heavy snowfall event.

Published by Copernicus Publications on behalf of the European Geosciences Union. 
Similar events don't only happen in mountain regions, but also in the plain, as the one which occurred in the PoValley, close to the city of Ferrara and Piacenza on the 10 March 2010. In this case, many long black-outs, due to medium voltage grid failures, pained 25000 end-users.

A survey on a database containing medium and low voltage failure data, since 1999 to 2004, highlights that more than 4000 independent failures on the medium voltage grid occurred during winter (Bonelli et al., 2008). In that study, it is shown that most of the failures can be linked to snowfall events characterised by the air temperature ranging between $0{ }^{\circ} \mathrm{C}$ and $2{ }^{\circ} \mathrm{C}$, and occurring more than $12 \mathrm{~h}$ with a wide range of wind intensity. The wind intensity plays different roles, since power lines can sometimes collapse due to the combined action of wind intensity and ice load (Bonelli et al., 2008).

\subsection{Defence strategies}

The first defence strategy is to adopt correct building criteria for power lines, well calibrated on the climate of the region where they cross. Power lines are usually built following climatic hardiness rules (IEC, 2003). In some countries, as in Italy, rules are only based on rough climatic evaluation by the altitude and latitude of the terrain where the power line will be built. But, as stated above, most of accidents occurred below the altitude of $1000 \mathrm{~m}$ a.s.l., in regions where terrain ranges between $100 \mathrm{~m}$ a.s.l. and $4000 \mathrm{~m}$ a.s.1.!

In many countries where power line icing is a relevant problem, some strategies are taken into account in order to mitigate or avoid the effect of this phenomenon on the reliability of the power supply service. A wide presentation of these techniques can be found in the specific Cigrè Report (Cigrè, 2009). Some of these strategies, such as wire heating, are justified for their costs only in the countries where the icing problem is frequent. Other protection systems are passive methods, as the one tested by Italian $\mathrm{TSO}^{1}$ (TERNA) on $132 \mathrm{kV}$ power line in Valle Stura (Cuneo, Piedmont region) during the 2009-2010 winter season. It consists of using counterweights that increase the torsional stiffness of conductors. Field observations demonstrate that this device can limit the formation of cylindrical deposits of wet snow on conductors, as shown in Fig. 1.

Other defence strategies, when building solutions are not available for economic reasons, are based on power dispatching, devoted to minimize the supply failures as used by some TSO. In this case, a good prediction of icing phenomena a few days before the event is necessary.

In some countries, the tendency is to develop icing forecast systems by the combination of Numerical Weather Prediction (NWP) output and ice accretion models. Probably, the best attempts to connect wet snow accretion models and weather forecasting models were developed in Iceland

\footnotetext{
${ }^{1}$ Transmission System Operator
}

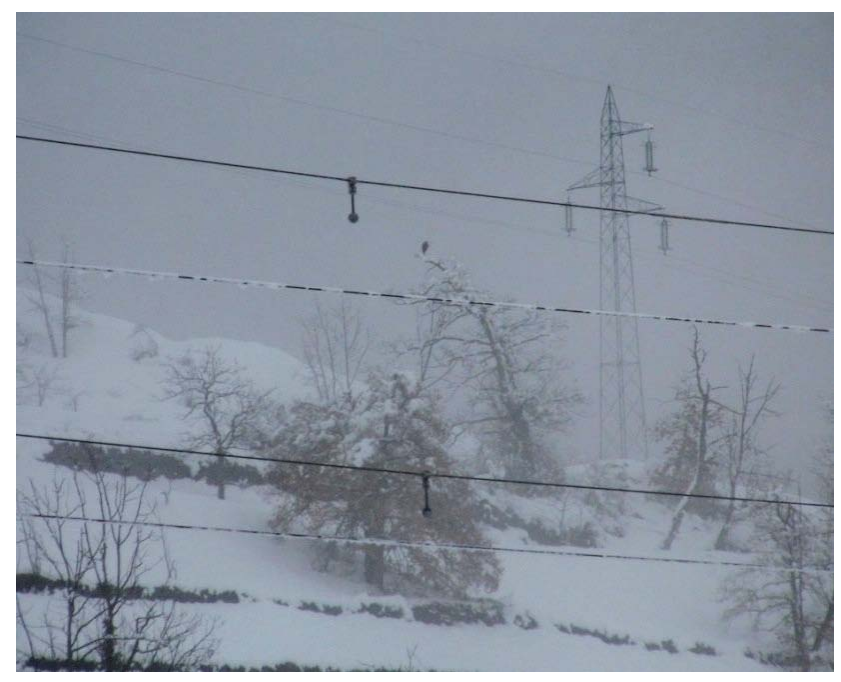

Fig. 1. Counterweights on a $132 \mathrm{kV}$ power line limit the wet snow accretion on wires (Valle Stura - Piedmont - Italy; 19 February 2010).

(Olafsson et al., 2002a, b; Farzaneh, 2008). Their model also includes a realistic description of the mountain effect of some important meteorological processes.

Another important project is developed in UK by using the Weather Research Forecast model (WRF) combined with a wet snow accretion model (Wareing and Nygaard, 2009). This system was successfully used to simulate the ice accretion on conductors during a strong event in central England in 1990 that caused some accidents and failures. The results demonstrated the feasibility for applying that forecast system to the entire UK.

The Hungarian Meteorological Service developed a forecast method after testing different weather models with various microphysical schemes. Comparisons with observations have been carried out too. The results show that a detailed hydrometeor description is suitable to improve the forecast skill (Toth et al., 2009). They also used the model to calculate the return period of the strongest events.

In this paper, a prediction and alert system, named WOLF (Wet snows Overload aLert and Forecast) is presented. It was developed to provide a tool for the Italian TSO, able to analyse and forecast the icing hazard over the whole country, together with information on the power lines. Some WOLF highlights are: interactivity and availability via Internet, simplicity in use for non-meteorologist people too.

The main WOLF applications are:

- to supply an on-line alert system for the electric grid management;

- to provide an off-line work instrument for meteorologists, grid planning engineers and "Regulation Authorities". 


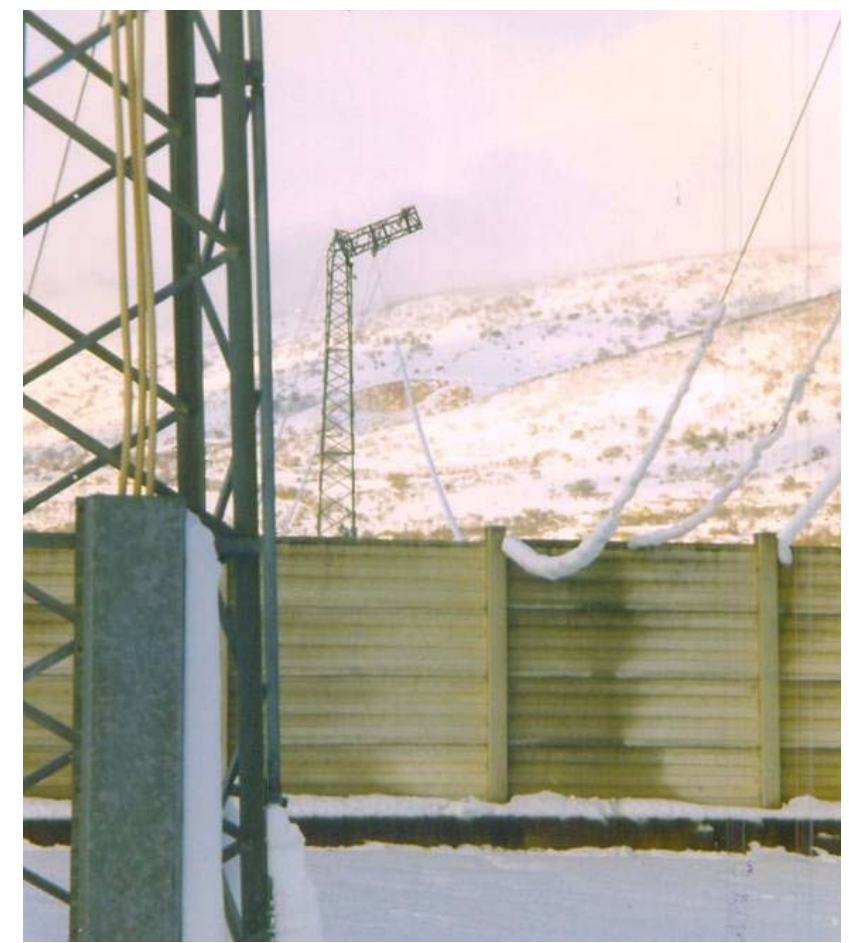

Fig. 2. Tower collapse due to overload ice on conductors during a wet snow event (Puglia - Italy; winter 1995).

In fact, if climatic evaluations are required for the design of new lines and local measurements are not available, the model remains the only tool for this purpose.

Description of the system and its application during the cold season 2009-2010, are presented in the following Sects. 2 and 3.

\section{The WOLF system}

The aim of WOLF is to forecast wet snow events and calculate maximum ice-load expected on conductors with different diameters in a target area. Every day, the ice-load hazard level is plotted on a map in order to supply a daily-warning. The system helps power network management to use electricity dispatching solutions. WOLF integrates an ice accretion model, an interface for the collection of forecasted meteorological data and a GIS ${ }^{2}$ display system. Before describing WOLF, a brief explanation of the physics of the wet snow process and accretion follows.

\subsection{The wet snow precipitation and the accretion process on overhead power lines}

Atmospheric icing is a complex phenomenon that involves several physical processes (Cigrè, 2005). Many meteorological variables are relevant, such as: air temperature, amount

\footnotetext{
${ }^{2}$ Geographical Information System
}

of precipitation, wind intensity and its direction, hydrometeor phase and size distributions. These parameters strictly influence the rate of ice accretion on overhead power lines and the possible ice shedding. There are different types of icing accretion, but in this article it will be treated as only the wet snow type, due to its strong influence on power lines in Italy. In fact, as shown in the introduction, most of the service outages and failures are caused by heavy wet snow meteorological conditions.

Wet snow precipitation generally occurs when the surface air temperature is close to freezing point (Makkonen, 1989; Sakamoto, 2000). There is not an exact temperature range for wet snow conditions, but the most well-known interval, verified by many observations in different countries, is within the range $0-2{ }^{\circ} \mathrm{C}$. In this positive temperature layer, the snowflakes can partially melt and their typical liquid water content (LWC) is within the range of $15 \%-40 \%$ of the total mass. Under these conditions, the snowflakes settle on the conductor and join together not only by the mechanism of collision, but also for the strong coalescence due to the presence of liquid water content in the snowflakes that promotes the growth of sleeve.

During every precipitation, the vertical temperature gradient of the atmosphere is proximally $6{ }^{\circ} \mathrm{C} \mathrm{km}^{-1}$ (Fikke, 2005a, b; Fikke et al., 2007). Wet snow is generally associated with an unstable layer, in which snowflakes fall from a colder air mass to a warmer layer near the surface. It is also important to estimate the elevation of $0^{\circ} \mathrm{C}$ isotherm, in order to evaluate the exposure time of snowflakes above freezing point temperatures, that may increase their liquid water content. It is clear that one of the most critical parameters is the accuracy of the forecasted air temperature, not only on the surface, but also along the overall vertical air profile, in which the physical processes take place. The typical duration of wet snow events is $18-24 \mathrm{~h}$, producing snow sleeves up to $15 \mathrm{~cm}$ in diameter and causing an extra load on conductors up to $8-10 \mathrm{Kg} \mathrm{m}^{-1}$ (Admirat and Sakamoto, 1988a, b). This overload can produce serious damage to overhead lines, exceeding the mechanical resistance of lattice tower supports, as shown in Fig. 2. In some cases, the conductor undergoes an extra load due to the intense wind blowing after the accretion event.

\subsection{Meteorological variables involved}

The ice accretion model in WOLF requires forecasted meteorological variables in order to compute the maximum overload of ice sleeves on conductors during a wet snow precipitation. The most important data, as stated by other authors, are: the surface air temperature, precipitation amount expressed in water equivalent, the height of $0{ }^{\circ} \mathrm{C}$ and $2{ }^{\circ} \mathrm{C}$ isotherm, $10 \mathrm{~m}$ wind intensity (Fikke, 2005a, b; Gland and Admirat, 1986; Olafsson et al., 2002a, b; Wareing and Nygaard, 2009). It is assumed that a precipitation amount for the whole event of less than $10 \mathrm{~mm}$ cannot produce an important 


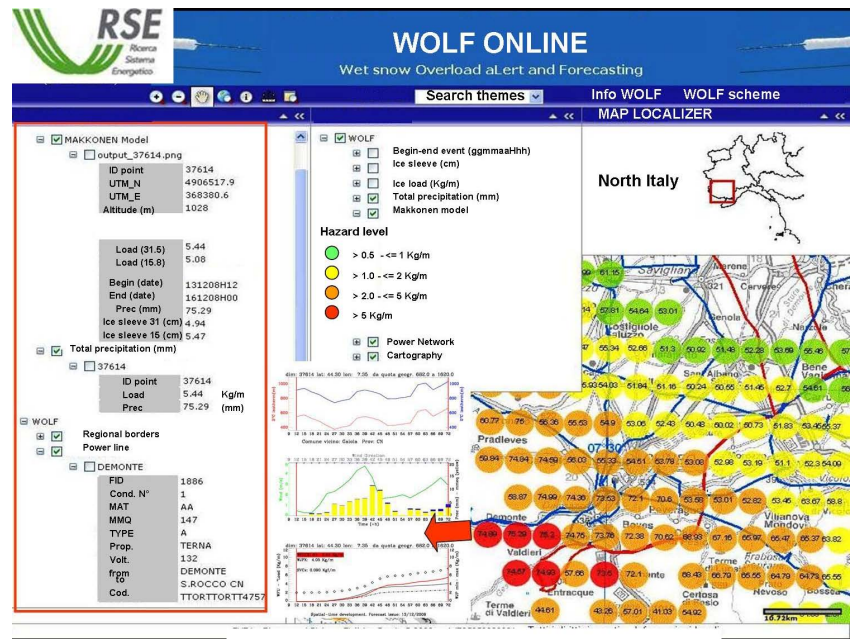

Fig. 3. Web-GIS interactive tool map: wet snow hazard and power line information is available clicking each grid point.

snow overload expected to strike a power line. For this reason, these weak events are not considered. The meteorological variables, that must be provided to WOLF, come from a non-hydrostatic numerical weather prediction model on a regular grid with a mesh of about $5 \mathrm{~km}$. They are forecasted every day up until $+72 \mathrm{~h}$ in advance with a time-step equal or less than $3 \mathrm{~h}$. Because of the variability of terrain altitude in a $5 \mathrm{~km}$ mesh, the air temperatures at the minimum and maximum altitude are estimated. The occurrence of accretion process is determined by the intersection of this temperature interval with the $0-2{ }^{\circ} \mathrm{C}$ range. For this purpose, an higher resolution $\mathrm{DEM}^{3}$ is used and a vertical temperature gradient of $6^{\circ} \mathrm{C} \mathrm{km}^{-1}$ is supposed.

\subsection{Accretion model}

Unfortunately, there is no specific accretion model that can well simulate all physical and mechanical processes involved in ice accretion. This statement is particularly true for wet snow icing (Admirat et al., 1988). For this reason, the rough model still used today may be improved only after collecting more detailed data from field observations.

Field data are complementary to the laboratory ones (Admirat and Sakamoto, 1988a, b) and they enable us to tune the accretion models by using empirical coefficients for some complex physical processes. In fact, taking into account the mass conservation equation (Makkonen, 1984, 2000):

$\frac{d M}{\mathrm{~d} t}=\alpha_{1} \alpha_{2} \alpha_{3} \times q \times A \times V$

where:

$M$ is the mass accreted on the object $(\mathrm{kg})$, $t$ is the time (s),

\footnotetext{
${ }^{3}$ Digital Elevation Model
}

$\alpha_{1}$ is the collision efficiency (dimensionless), $\alpha_{2}$ is the sticking efficiency (dimensionless), $\alpha_{3}$ is the accretion efficiency (dimensionless),

$w$ is the concentration of liquid and solid water in air $\left(\mathrm{kg} \mathrm{m}^{-3}\right)$,

$A$ is the cross-sectional area of the object $\left(\mathrm{m}^{2}\right)$,

$V$ is the wind intensity (perpendicular to accreting object) $\left(\mathrm{m} \mathrm{s}^{-1}\right)$,

The effects of many micro-scale processes are enclosed in the empirical coefficients $\alpha_{1} \alpha_{2} \alpha_{3}$. These range between 0 and 1 and represent the mechanisms that reduce the contribution of the precipitating mass to the ice load on the conductor.

For a vertical wet snow precipitation, the resulting value of $w \times V$ is equivalent to the intensity of the precipitation measured by a rain-gauge. The presence of wind raises this term, as will be explained in Eq. (4).

The $\alpha_{1}$ coefficient depends on the size of the particles, and it is near to 1 for big particles as snowflakes; $\alpha_{2}$, the sticking efficiency, is proportional to the liquid water content of snowflakes and depends on the wind intensity. The last coefficient $\alpha_{3}$ is the accretion efficiency and it is reduced from the unity in the case of wet snow, when part of the accreted mass leaves the conductor by the dripping process or shedding, depending on the liquid water content in the sleeve and how this is distributed in the ice matrix.

The dependence of $\alpha_{2}$ from the wind intensity is given by the expression in Eq. (2):

$\alpha_{2}=1 \quad$ if $V<1 \mathrm{~m} \mathrm{~s}^{-1} ; \quad \alpha_{2}=\frac{1}{V} \quad$ if $1<V<10 \mathrm{~s}^{-1}$

where $V$ is the wind intensity in $\mathrm{ms}^{-1}$ (Admirat and Sakamoto, 1988a, b).

In this work, the goal of the authors is to use a simplified version of the previous model, in order to make it easier the forecast computation. The method, as proposed by Hungarian Meteorological Service (Toth et al., 2009) and applied to a cylindrical conductor, is:

$\Delta M=P \times R \times \Delta t \times \gamma$

where:

$\Delta M$ is the increasing amount of the accumulated wet snow on a unit length of conductor $\left(\mathrm{kg} \mathrm{m}^{-1}\right)$,

$P$ is the flux of mass of wet-snow or the intensity of total precipitation $\left(\mathrm{kg} \mathrm{m}^{-2} \mathrm{~h}^{-1}\right)$,

$R$ is the outer radius of ice sleeve (m),

$\Delta t$ is the time step in which meteorological variables are provided by the NWP model (h).

$\gamma$ is a dimensionless coefficient which takes into account the total reductive effect of $\alpha_{1}, \alpha_{2}, \alpha_{3}$.

The volume of ice sleeve can be calculated by assuming a typical value of snow density equal to $400 \mathrm{~kg} \mathrm{~m}^{-3}$. In the first time step, integrating Eq. (3), the value of $R$ is the conductor radius. WOLF considers 3 reference diameters $(31.5 \mathrm{~mm}$, $22.8 \mathrm{~mm}, 15.8 \mathrm{~mm}$ ), that are the most commonly used in an 

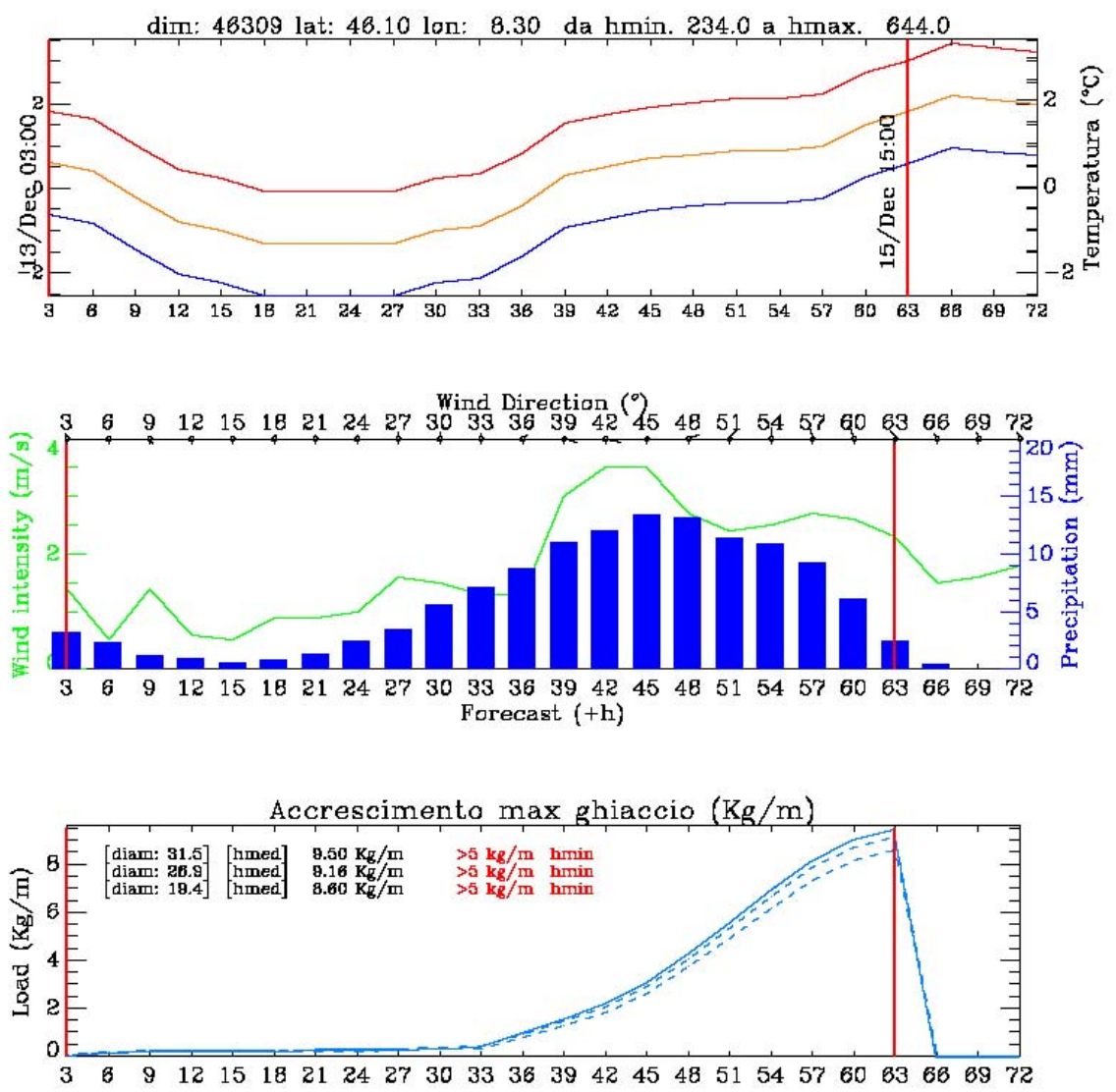

Fig. 4. Time diagramme of a major wet snow event referred to: (Ossola Valley - Piedmont - Italy; 13-15 December 2008).

Italian power grid. The empirical coefficient $\gamma$ has been set to 1 in WOLF procedure because it is preferred to consider the worst condition of ice accretion for alerting purpose. This value may clearly overestimate the ice load, but a more suitable value can be considered only defining the contribution of some microphysical processes, as shedding and dripping, until now unknown. This is one of the reasons for which the authors started in 2007, a continuous experimental campaign programme in different regions of Italy (Bonelli and Lacavalla, 2009). This activity is explained in Sect. 3. Equation (3) is integrated during the whole wet-snow event. An event, predicted by WOLF in every grid point, is defined as a time interval in which the snowfall forecast is considered continuous and the snow sleeve around the conductor can grow, i.e., the meteorological variables as precipitation, temperature, wind intensity, are in the required range for starting and maintaining the process. In order to do that, the 3-hourly forecast variables are separately analysed for each mesh of $5 \times 5 \mathrm{~km}^{2}$. A wet snow icing event is detected applying specific criteria: principally, the extreme temperature interval in each point must intersect the typical range values of the wet snow event: $0-2{ }^{\circ} \mathrm{C}$.
In Eq. (3), the wind intensity does not appear, but it should be taken into account because it contributes to the flux of snow mass $P$ as shown in Eq. (4).

$P=P_{0}{\sqrt{1+\left(\frac{V \sin \Phi}{V_{\mathrm{s}}}\right)^{2}}}^{2}$

where:

$P_{0}$ is the precipitation intensity measured or forecasted at the ground ( $\mathrm{mm} \mathrm{h}^{-1}$ or $\mathrm{kg} \mathrm{m}^{-2} \mathrm{~h}^{-1}$ ),

$V$ is the wind intensity at the conductor height $\left(\mathrm{m} \mathrm{s}^{-1}\right)$,

$\theta$ is the angle between the wind direction and the conductor supposed horizontal,

$V_{\mathrm{s}}$ is the vertical velocity of snowflakes $\left(\mathrm{m} \mathrm{s}^{-1}\right)$.

Despite the correct formulation of Eq. (4) that can lead to an increase of $P$ with respect to $P_{0}$, some approximations have been introduced in WOLF, considering the follow statements.

- $V_{\mathrm{S}}$ is difficult to forecast or to measure routinely by synoptic weather stations. During our experimental campaigns, some values of $V_{\mathrm{s}}$ have been measured with a 

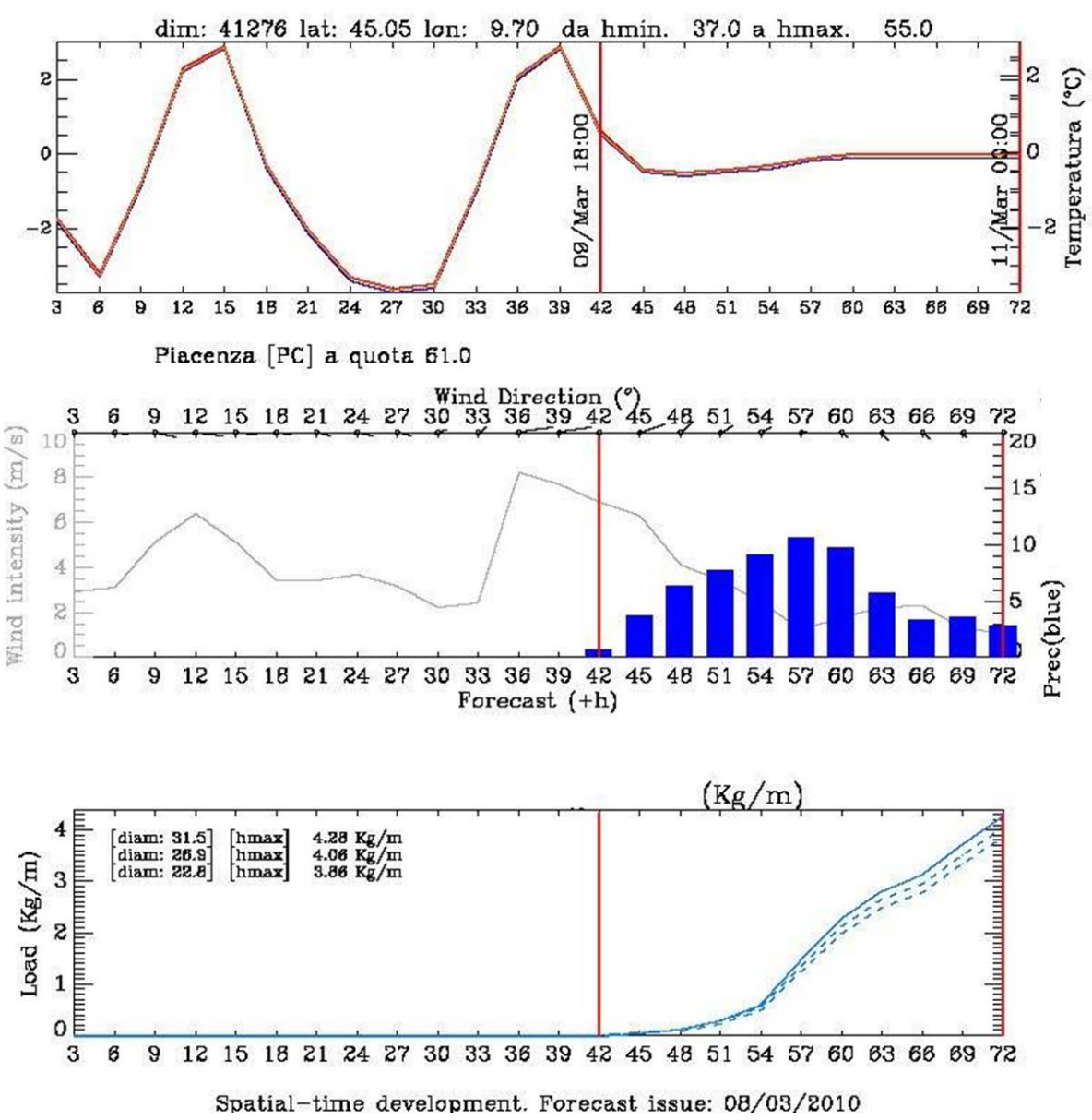

Fig. 5. Time diagramme referred to the Piacenza case on 08-10 March 2010.

laser precipitation monitoring (disdrometer), finding a typical figure of $2 \mathrm{~m} \mathrm{~s}^{-1}$.

- $V$ should be given at the height of the conductor, but both synoptic measurements and NWP outputs provide the wind intensity at $10 \mathrm{~m}$ height and $\theta$ is also difficult to estimate in a mountain terrain.

- Many observations in Italy show weak winds, below $1 \mathrm{~m} \mathrm{~s}^{-1}$, during wet snow conditions.

These arguments led us to consider $P=P_{0}$ in the first prototype version of WOLF. On the contrary, in the new release that will be operative in order to alert grid operators, the need to consider the worst possible condition forces us to compute $P$ by Eq. (4) with the forecasted value $V$ and the angle $\theta$ set to $90^{\circ}$.

Another important factor that should be taken into account in the model is the Joule effect heating, caused by the electric current flowing in the conductor and triggering the ice accretion. Some measurements of this effect have been carried out in the experimental campaign activity and the influence of Joule heating on the start-up of the accretion process will be introduced in the next version of WOLF. At the moment, WOLF doesn't take into account any electric current in the conductor.

\subsection{The WOLF output and WEB-GIS display}

WOLF forecast outputs are reported in a WEB-GIS Active Desktop, easy-accessible by the staff of Power Grid Maintenance Department of TERNA, the Italian TSO. The interactive WEB-GIS tool map allows us to display a large amount of information, as shown in Fig. 3.

First of all, the forecast hazard level of the expected maximum ice load $\left(\mathrm{kg} \mathrm{m}^{-1}\right)$, calculated by Eq. (3) on the 3 conductor diameters, is plotted over a geographical base map in which the power lines are reported as well.

The ice-load hazard level has been set into 4 intervals as reported below, by using a typical colour scale, from green to red:

$$
\begin{aligned}
& -0.5 \mathrm{Kg}-1 \mathrm{Kg} \mathrm{m}^{-1} \text { : green } \\
& -1 \mathrm{Kg} \mathrm{m}^{-1}-2 \mathrm{Kg} \mathrm{m}^{-1} \text { : yellow }
\end{aligned}
$$


Table 1. Principal electrical accidents occurred during the WOLF simulation period.

\begin{tabular}{|c|c|c|c|c|c|}
\hline Date & Site & $\begin{array}{l}\text { Failure type } \\
\text { (from the press) }\end{array}$ & Power line & $\begin{array}{l}\text { Wolf prediction } \\
\text { Ice load } \\
\left(\mathrm{kg} \mathrm{m}^{-1}\right)\end{array}$ & $\begin{array}{l}\text { Wolf prediction } \\
\text { Ice-sleeve } \\
\text { thickness }(\mathrm{cm})\end{array}$ \\
\hline $\begin{array}{l}\text { From } 13 \text { to } \\
16 / 12 / 2008\end{array}$ & $\begin{array}{l}\text { Biella, Cuneo, Verbania } \\
\text { (Piedmont) }\end{array}$ & $\begin{array}{l}\text { Black-out afflicted more } \\
\text { than } 50000 \text { users }\end{array}$ & $\begin{array}{l}\text { Medium and } \\
\text { high voltage } \\
\text { grid }\end{array}$ & 10.6 & 13.5 \\
\hline 28/04/2009 & $\begin{array}{l}\text { Gressoney } \\
\text { (Valle d'Aosta) } \\
1800 \text { m a.s.l. }\end{array}$ & $\begin{array}{l}22.8 \mathrm{~mm} \text {. conductor broke } \\
\text { down }\end{array}$ & $132 \mathrm{kV}$ & 12.4 & 18 \\
\hline $10 / 03 / 2010$ & $\begin{array}{l}\text { Ferrara and Piacenza } \\
\text { (Emilia Romagna) }\end{array}$ & $\begin{array}{l}\text { Diffuse and prolonged } \\
\text { black-outs pained } \\
25000 \text { users }\end{array}$ & $\begin{array}{l}\text { Medium } \\
\text { voltage grid }\end{array}$ & $\begin{array}{l}\text { Ferrara: } 1.2 \\
\text { Piacenza: } 4.3\end{array}$ & $\begin{array}{l}\text { Ferrara: } 3.2 \\
\text { Piacenza: } 9.2\end{array}$ \\
\hline
\end{tabular}

$$
\begin{aligned}
& -2 \mathrm{Kg} \mathrm{m}^{-1}-5 \mathrm{Kg} \mathrm{m}^{-1}: \text { orange } \\
& ->5 \mathrm{Kg} \mathrm{m}^{-1}: \text { red }
\end{aligned}
$$

These values have been chosen by referring to the building design criteria of overhead lines. Other works, lead by Admirat (Admirat and Sakamoto, 1988a, b) and considering a historical database of "wet snow days" in French climatic stations, calculated the hazard reference levels by using the return period (year) of simulated ice-load accretions.

The "warning value" is set $>5 \mathrm{~kg} \mathrm{~m}^{-1}$ and when it happens, an alert is displayed on the active desktop where the user can obtain further important and detailed information about the event. In particular, in WOLF, each single wet snow episode shown in the map is characterised by:

- the altitudes concerned by wet-snow atmospheric layer $\left(0{ }^{\circ} \mathrm{C}-2{ }^{\circ} \mathrm{C}\right)$;

- the precipitation amount (water equivalent in $\mathrm{mm}$ ) in the area;

- the solid fraction of snow precipitation (in $\mathrm{mm}$ );

- the wind intensity $\left(\mathrm{m} \mathrm{s}^{-1}\right)$ and its direction $\left(^{\circ}\right)$ during and after the event;

- the duration of wet-snow event (in hours);

- the label "icing" or "melting", to represent the conditions after the events;

- the stress forces on conductors due to ice-load and wind intensity;

- the diameters of ice-sleeves accreted on 3 reference conductors.
Additional data are available in the WEB-GIS map as:

- the high-voltage power lines network (132, 150, 220 and $380 \mathrm{kV}$ ) with some additional information;

- the electric grid information;

- the raster cartography of Italy 1:750:000;

- the Digital Elevation Model (DEM) with $250 \mathrm{~m}$ grid spacing;

- the administrative boundaries of Italy.

The procedure provides, for each single wet-snow event, the time evolution of the episode. With 3-hourly forecasted weather data, the development of a snow event can be represented by the air temperature, total amount of precipitation, wind intensity and direction. At each point, the mass and diameters of snow sleeves have been plotted in a time diagram, as shown in Fig. 4.

It is important to underline that the warnings issued by WOLF are "potential warnings" taking into account only the necessary weather conditions for wet-snow accretion; for this reason the False Alarm Rate (FAR) may be high, although the total number of warnings is still small compared to the snow event frequency. Only after a field verification is it possible to correctly compute the FAR. According to this need, a WEBGIS archive in WOLF is queried, providing model data that might be attached to the available observations, as shown in Fig. 7 .

\section{WOLF application during the period 2009-2010}

From November 2009 to April 2010, WOLF ran routinely every day, producing an icing forecast of the entire Italian territory. Because of the occurrence of other important events in December 2008, WOLF was also tested in these cases. 

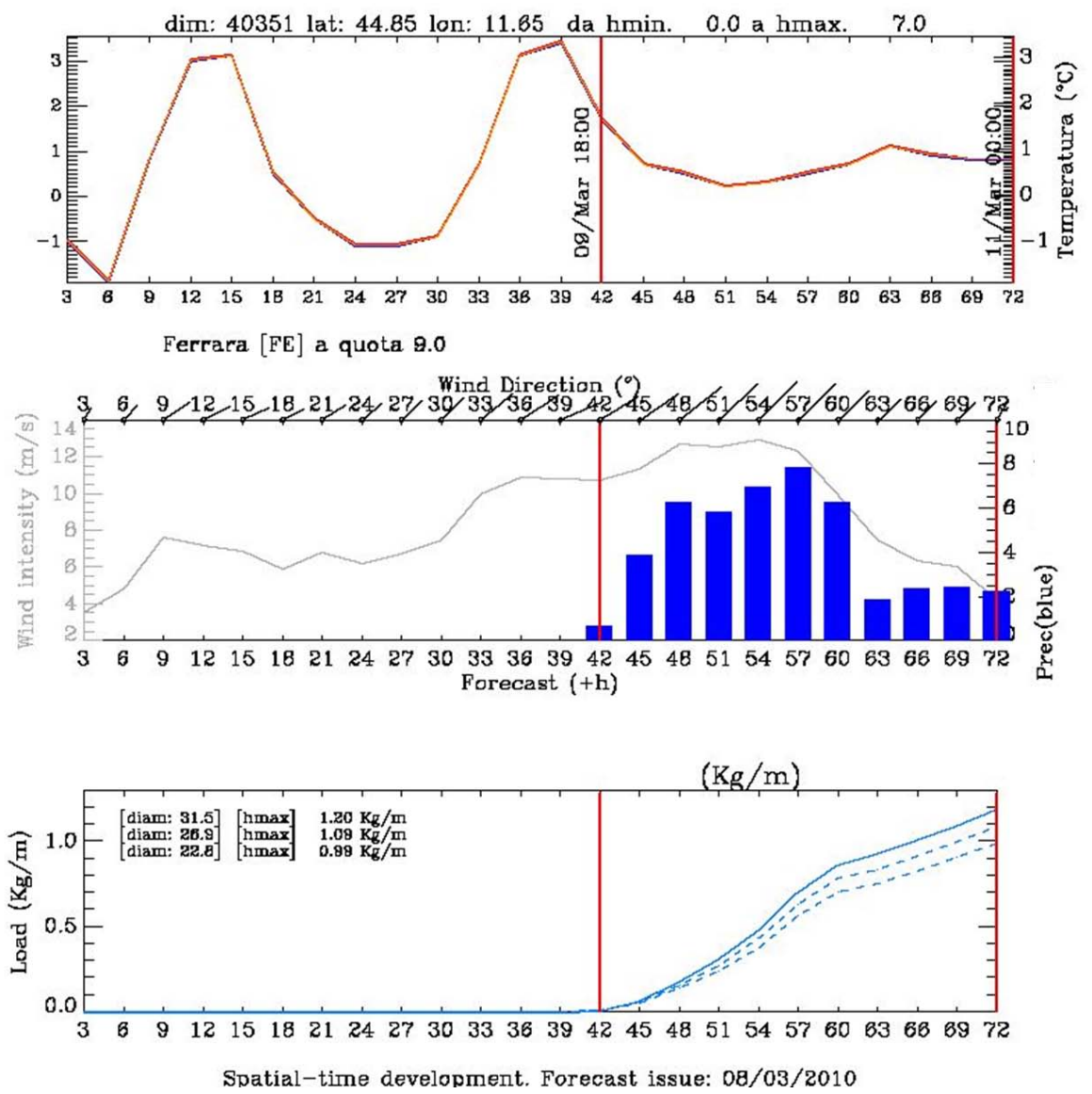

Fig. 6. Time diagram referred to the Ferrara case on 08-10 March 2010.

The simulation outputs allowed the authors to compare the forecasts with the only available information about the electrical accidents: the press articles. During the same period, some field campaigns have been carried out in order to collect detailed and local measurements (Bonelli et al., 2009), as explained further.

WOLF has been fed by the non-hydrostatic numerical weather prediction model LAMI (Limited Area Model Italy), developed in the framework of the $\mathrm{COSMO}^{4}$ Project and managed by ARPA - Emilia Romagna. The model has a $7 \mathrm{~km}$ horizontal resolution, 41 vertical levels and it provides the principal local meteorological variables at medium range in time till $+72 \mathrm{~h}$. Every output field has been reported to the WOLF horizontal grid with a spatial resolution of $5 \mathrm{~km}$, by using a spatialization algorithm. This step is necessary to allow the feeding by other numerical weather models.

Every day WOLF produces $\mathrm{a}+72 \mathrm{~h}$ forecast of ice load accumulated on conductors of different diameters during wetsnow precipitations. Some case studies have been analysed

${ }^{4}$ COSMO is an international Consortium between Germany, Poland, Switzerland, Greece and Italy; for further information: www.cosmo-model.org during observed failures in the power line grid and the whole period output to evaluate the rate of false alarm. The accidents which occurred in the period of the simulation, are reported in the Table 1.

In the Piedmont case, between the 13 and 16 December 2008, a heavy and wide snowfall caused many power line failures. The forecast of the total precipitation amount reached $150 \mathrm{~mm}$ and WOLF forecasted an ice-load of more than $10 \mathrm{~kg} \mathrm{~m}^{-1}$ on the $22.8 \mathrm{~mm}$ conductor. The snow depth registered in different areas of Piedmont as in Stura and Ossola valleys, reached $1.5 \mathrm{~m}$ on the ground. The WOLF forecast for the Ossola valleys is shown in Fig. 4. In the Gressoney case (28 April 2009), when a $22.8 \mathrm{~mm}$ conductor broke down at an altitude of $1800 \mathrm{~m}$ a.s.l., WOLF forecasted an ice load greater than $12 \mathrm{~kg} \mathrm{~m}^{-1}$ and a precipitation amount of $113 \mathrm{~mm}$, that was confirmed by local observations $(143 \mathrm{~mm}$ registered by the heating rain gauge of Gressoney S. J.). Figure 8 shows a zoom of the Gressoney area on the WOLF display.

The Emilia Romagna events (10 March 2010) were characterised by prolonged and wide spread snowfall combined with wind intensity till $10 \mathrm{~m} \mathrm{~s}^{-1}$ in the east part of the area 


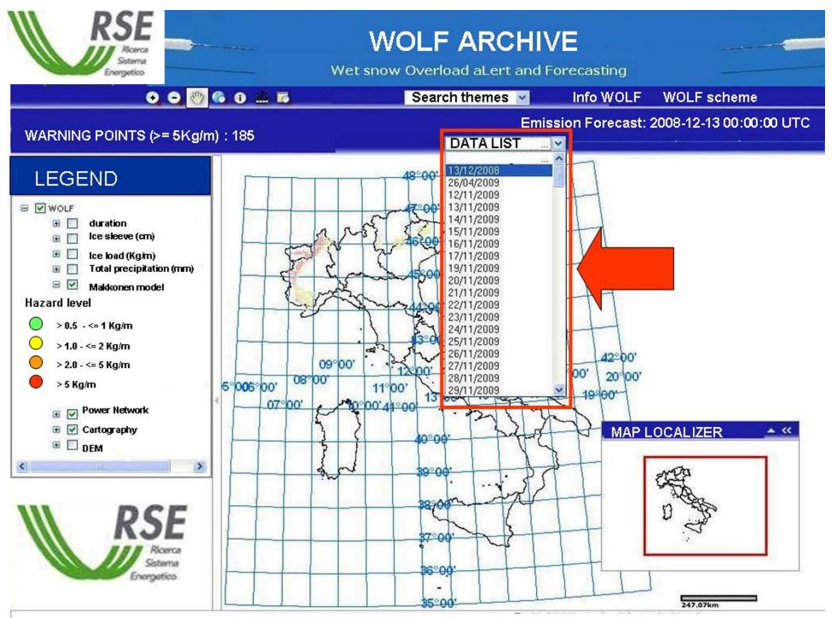

Fig. 7. Web-GIS Archive tool: it is possible to download and visualize each event stored in the Archive, through the data list menu.

(Ferrara) and even with wind gusts of $25 \mathrm{~m} \mathrm{~s}^{-1}$ on the coast of Romagna. In particular, the total precipitation amount (rain + snow) forecasted was 47 and $65 \mathrm{~mm}$, respectively, at Ferrara and Piacenza. Some local and different observations were available: a total precipitation (rain + snow) of $17 \mathrm{~mm}$ at Ferrara, and $37 \mathrm{~mm}$ at Piacenza. Despite the precipitation not being heavy in Ferrara, diffuse and protracted black-outs afflicted thousands of users. In this case, it's reasonable to assume that the wind intensity was the main cause of electrical outages due also to indirect effects, as trees fell on the overhead lines. Conversely, the city of Piacenza was afflicted by a strong wet-snowfall and the accidents were principally due to the ice overload on conductors.

The accretion model in WOLF provided a value of 1.2 and $4.3 \mathrm{~kg} \mathrm{~m}^{-1}$ for Ferrara and Piacenza, respectively, with an ice sleeve thickness of 3.2 and $9.2 \mathrm{~cm}$. This difference is only due to the different amount of forecasted precipitation without any wind effect in the accretion model. Figures 5 and 6 show the time development of the event on the two sites forecasted by WOLF. Even though the poor available weather observations, the occurring events agree with the forecast of strong wind in Ferrara and heavy precipitation in Piacenza.

WOLF allowed the calculation of ice loads due to wet snow through the 2009-2010 season. The histogram in Fig. 11 reports the frequency of load classes forecasted by WOLF. Obviously, the first two lowest classes include most of the predicted cases $(86.8 \%)$. Fixing the value of $5 \mathrm{~kg} \mathrm{~m}^{-1}$, as the load alert threshold for a $31.5 \mathrm{~mm}$ conductor, it can be observed that the percentage of events, with a deposition greater than that fixed value, is $1.2 \%$ of the total number of wet snow events. These results seem to confirm a low number of dangerous events, important feature of a meteorological warning system. The histogram in Fig. 12 highlights that, most of the wet snowfall, occurs below $1500 \mathrm{~m}$ a.s.l. and only few cases $(5 \%)$ happened at a high altitude ( $>2000 \mathrm{~m}$ a.s.l.).

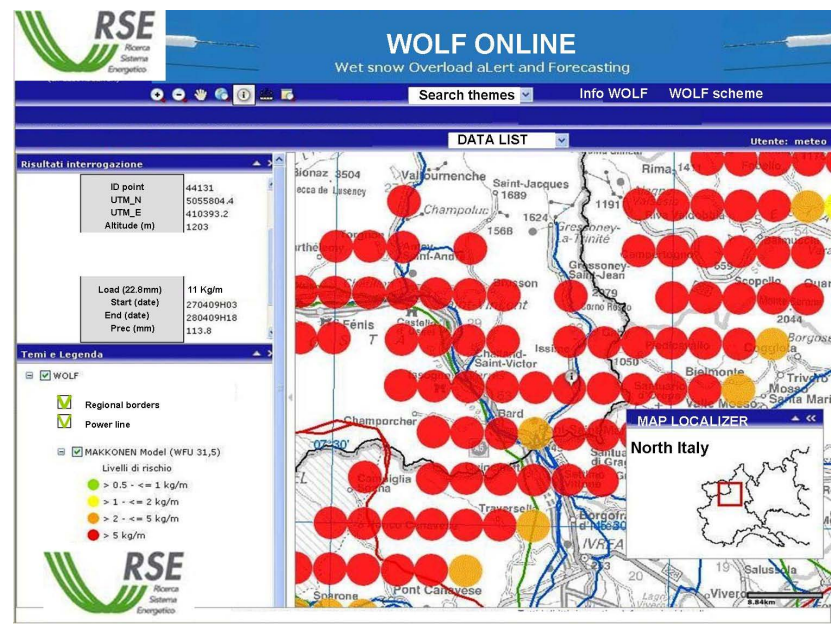

Fig. 8. Web-GIS Archive tools: the output of WOLF provided several alerts $\left(>5 \mathrm{Kg} \mathrm{m}^{-1}\right)$.

A deeper analysis is shown in Fig. 13, where the different iceload classes are divided for range of altitude. The lowest ice load class (1-2 $\mathrm{kg} \mathrm{m}^{-1}$ ) occurs under $1000 \mathrm{~m}$ a.s.l. (36\%), although higher load classes also happen at low altitude. The two highest loads presents no preferring altitudes.

For the season 2009-2010, the geographical distribution of ice load events, greater than $2 \mathrm{~kg} \mathrm{~m}^{-1}$, for a $31.5 \mathrm{~mm}$ conductor, are plotted in Fig. 10. In the map, it is evident that the most important events occurred both in mountain regions and in the plain. The Ossola Valley (Piedmont region) shows the highest frequency. The major loads forecasted by WOLF were in the Alpine region, but few events occurred also in the northern part of Apennines and in the Po valley.

Field measurements during wet-snow events are fundamental in improving the knowledge on the physical process, as well as the possibility to tune the ice accretion model on conductors (Cigrè, 2001; Thorsteins and Eliasson, 1998). The IEC 61774 rules (IEC, 1997) recommend a strategy for collecting different data sources in order to obtain the best possible information basis to evaluate the maximum design load.

For these reasons, the authors collected field data by means of mobile campaigns started on the 2007-2008 cold season (Bonelli and Lacavalla, 2009). In particular, in the 20092010 season, two campaigns have been lead in sites with different geographical characteristics. Some data from those campaigns have been compared with WOLF outputs: either the meteorological forecast and the ice loads. Snow accretion was measured on test conductors with a diameter of $31.5 \mathrm{~mm}$ free to rotate, being one of the typical conductors used in HV grid. Table 2 reports a selection of forecasted and observed data collected at Riale (Alpine valley in the Piedmont region) and nearby Alba (Po valley city in the Piedmont region). The forecasts are obtained from the 00:00 UTC model run on the same day of the campaign. 


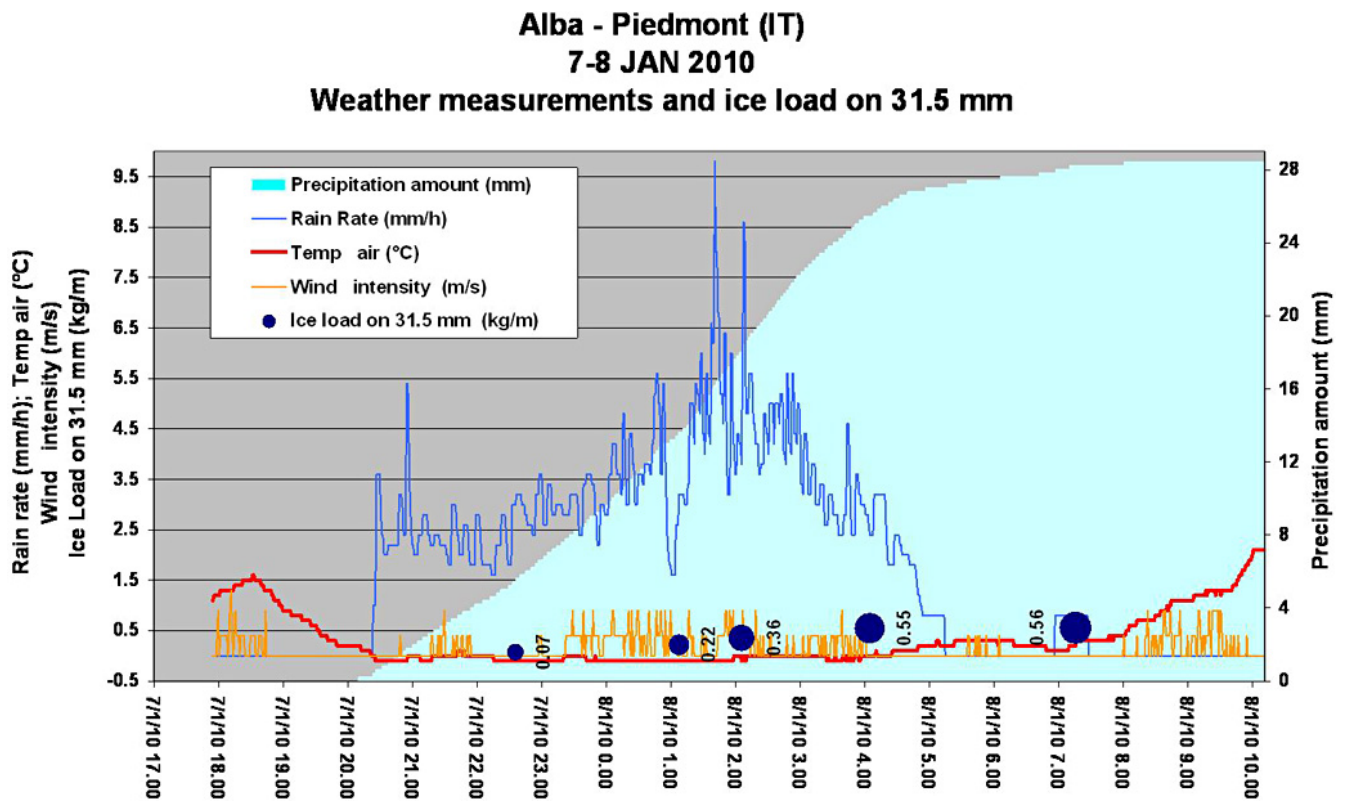

Fig. 9. Measurements collected during the experimental campaign of Alba (Piedmont; 7-8 January 2010).

In Fig. 9, the principal measurements are represented, collected during the experimental campaign of Alba on the 78 January 2010. The temperature decreased to $0^{\circ} \mathrm{C}$ before the beginning of the precipitation that started in the evening. During the whole event, the wind intensity remained low $\left(<1 \mathrm{~m} \mathrm{~s}^{-1}\right)$ not playing an important role for the ice accretion or shedding. The precipitation measured by a heated rain gauge for the whole event was $28 \mathrm{~mm}$, with a max rain rate of $9.5 \mathrm{~mm} \mathrm{~h}^{-1}$. In the figure, the size of the blue bubble points is proportional to the ice load with a maximum of $0.698 \mathrm{Kg} \mathrm{m}^{-1}$ on the morning of the 8 th. At the end of the event, the air temperature slightly increased, the snow turned into rain and the ice-sleeve fell down.

During the Riale event on the 29-30 March 2010, the temperature during the precipitation decreased below $0^{\circ} \mathrm{C}$, reaching a minimum value of $-1.6^{\circ} \mathrm{C}$. The wind was absent during the whole event and the total amount of precipitation was $47 \mathrm{~mm}$. Because of the low temperatures, the snowfall has had characteristics of dry-snow and the ice load on the conductor was rather limited not only for the low density of sleeve, but also for frequent ice shedding due to lack of cohesive forces.

The time-integrated values in Table 2 are referred to the whole snow event, whose time-interval is defined from the observations. In order to separate the performance of NWP model from that one of the accretion model used in WOLF, ice load is computed using the observed meteorological variables. It is important to underline that in both cases in Table 2, the observed average air temperatures were close to $0^{\circ} \mathrm{C}$ at Alba and slightly negative at Riale. The ice-load measurements show no severe values. Correctly, the WOLF

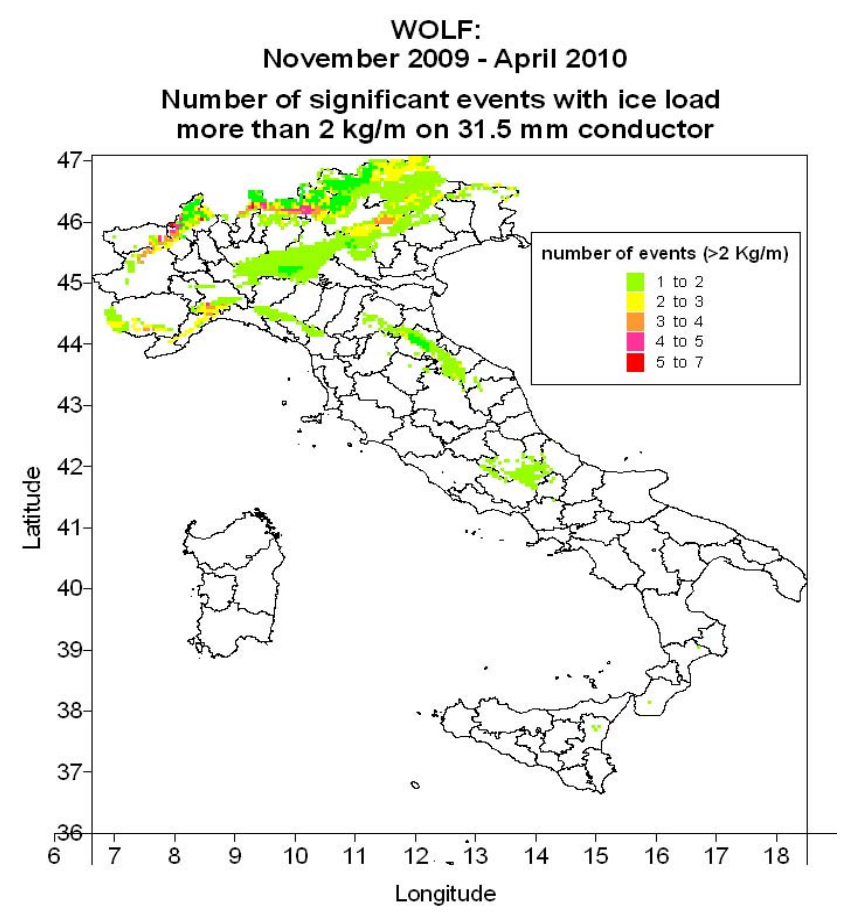

Fig. 10. Geographical distribution of significant events (ice load greater than $2 \mathrm{Kg} \mathrm{m}^{-1}$ ) forecasted by WOLF.

forecast did not issue any alerts. Table 2 shows that the precipitation amounts are well forecasted at Riale and slightly overestimated at Alba, while the average temperatures are quite well predicted in both cases. At Riale, the temperature decreased from 0.2 to $-1.6^{\circ} \mathrm{C}$ during the snowfall explaining 
Table 2. Synthetic results from two field campaigns and corresponding WOLF forecasts.

\begin{tabular}{lll}
\hline $\begin{array}{l}\text { Alba }(172 \mathrm{~m} \text { a.s.1.) } \\
\text { 7-8 Jan } 2010\end{array}$ & Forecast & Observation \\
\hline $\begin{array}{l}\text { Total precipitation amount }(\mathrm{mm}) \\
\text { Average air temperature }\left({ }^{\circ} \mathrm{C}\right)\end{array}$ & 35 & 28 \\
& -0.6 & 0 \\
Ice load on $31.5 \mathrm{~mm}$ conductor $\left(\mathrm{kg} \mathrm{m}^{-1}\right)$ & 0.87 & 0.7 \\
Ice density on $31.5 \mathrm{~mm}$ conductor $\left(\mathrm{kg} \mathrm{m}^{-3}\right)$ & 400 (const.) & 360 \\
& & \\
\hline & & \\
\hline $\begin{array}{l}\text { Riale }(1750 \mathrm{~m} \text { a.s.1.) } \\
\text { 29-30 Mar 2010 }\end{array}$ & Forecast & Observation \\
\hline $\begin{array}{l}\text { Total precipitation amount }\left(\mathrm{mm}^{-3}\right) \\
\text { Average air temperature }\left({ }^{\circ} \mathrm{C}\right)\end{array}$ & 46 & 42 \\
& -0.1 & -0.4 \\
& $($ decreasing from & $($ decreasing from \\
Ice load on $31.5 \mathrm{~mm}$ conductor $\left(\mathrm{kg} \mathrm{m}^{-1}\right)$ & -0.2 to -1.2$)$ & 0.2 to -1.6$)$ \\
Ice density on 31.5 mm conductor $\left(\mathrm{kg} \mathrm{m}^{-3}\right)$ & 400 (const.) & 0.3 \\
\hline
\end{tabular}

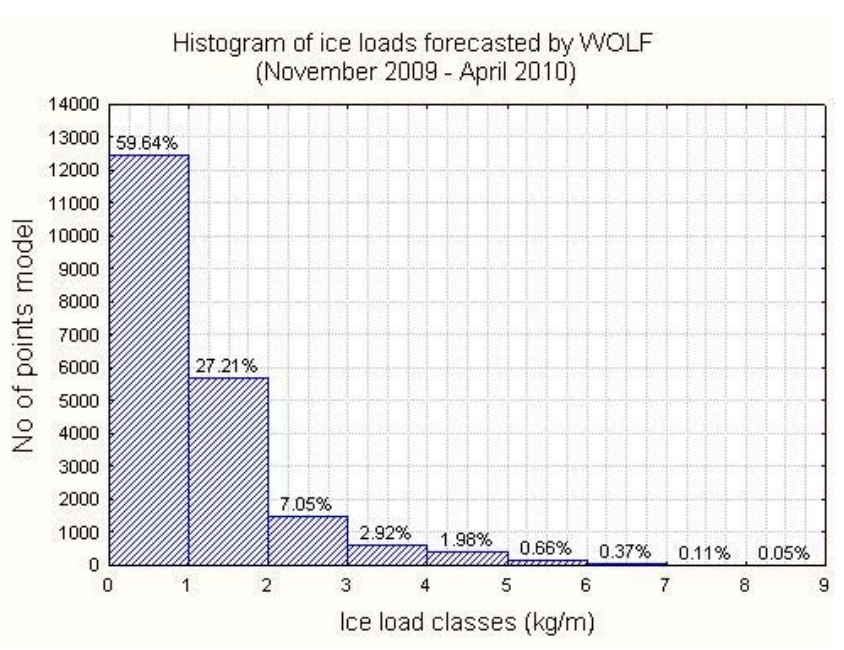

Fig. 11. Ice load frequency for the WOLF domain.

a dry-snow condition. On the contrary, at Alba, the temperature was slightly positive, according to the wet-snow observations. The ice-load forecast overestimated the measurements at Alba, but this fact could be explained by an over evaluation in the precipitation forecast.

Table 2 also shows the average ice density computed from radius and load measurements of the sleeve accreted on the 31.5 conductor. The Alba density value $\left(360 \mathrm{Kg} \mathrm{m}^{-3}\right)$ is quite similar to the constant one set in the model, but the Riale value is very low $\left(110 \mathrm{Kg} \mathrm{m}^{-3}\right)$, typical of a dry snowfall.

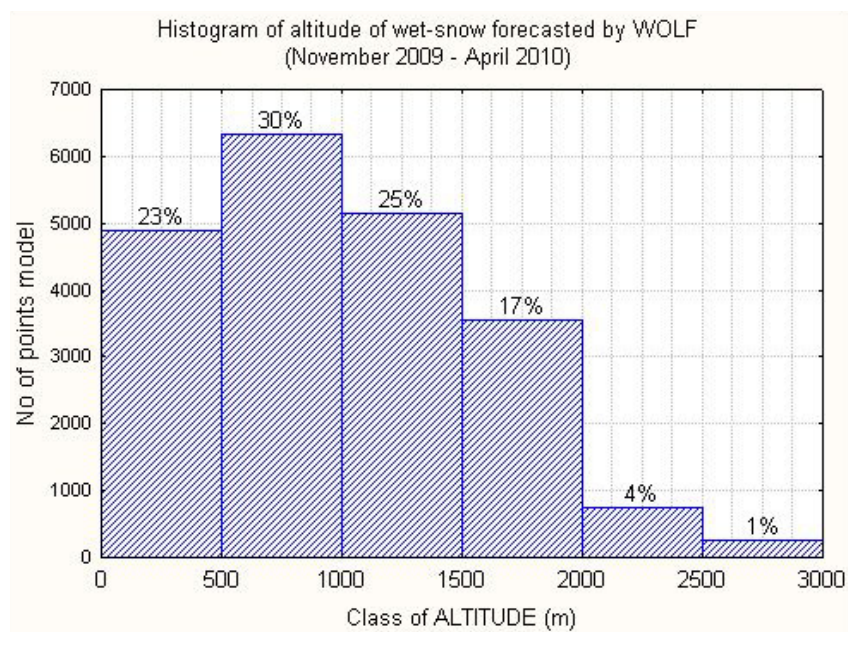

Fig. 12. Ice load frequency for the WOLF domain, divided into range of altitude.

The setting to 1 of the $\gamma$ coefficient in the model, seems to be correct for the wet-snow condition of Alba, including a high sticking efficiency and no shedding (see Sect. 2.3), that is verified by experimental data. On the other hand, in the Riale campaign, the fitting between model and observed data, forces the $\gamma$ coefficient to be 0.22 . In fact, the characteristics of the observed precipitation were completely different between Alba and Riale, in the last one the snowflakes had a very low liquid water content due to negative temperature.

These preliminary results put in evidence how the setting of $\gamma$ value, in order for the model to fit the observations, is critical because this coefficient ranges too much for little 


\section{Histogram of ice load forecasted by WOLF divided into range of altitude}

(November 2009 - April 2010)

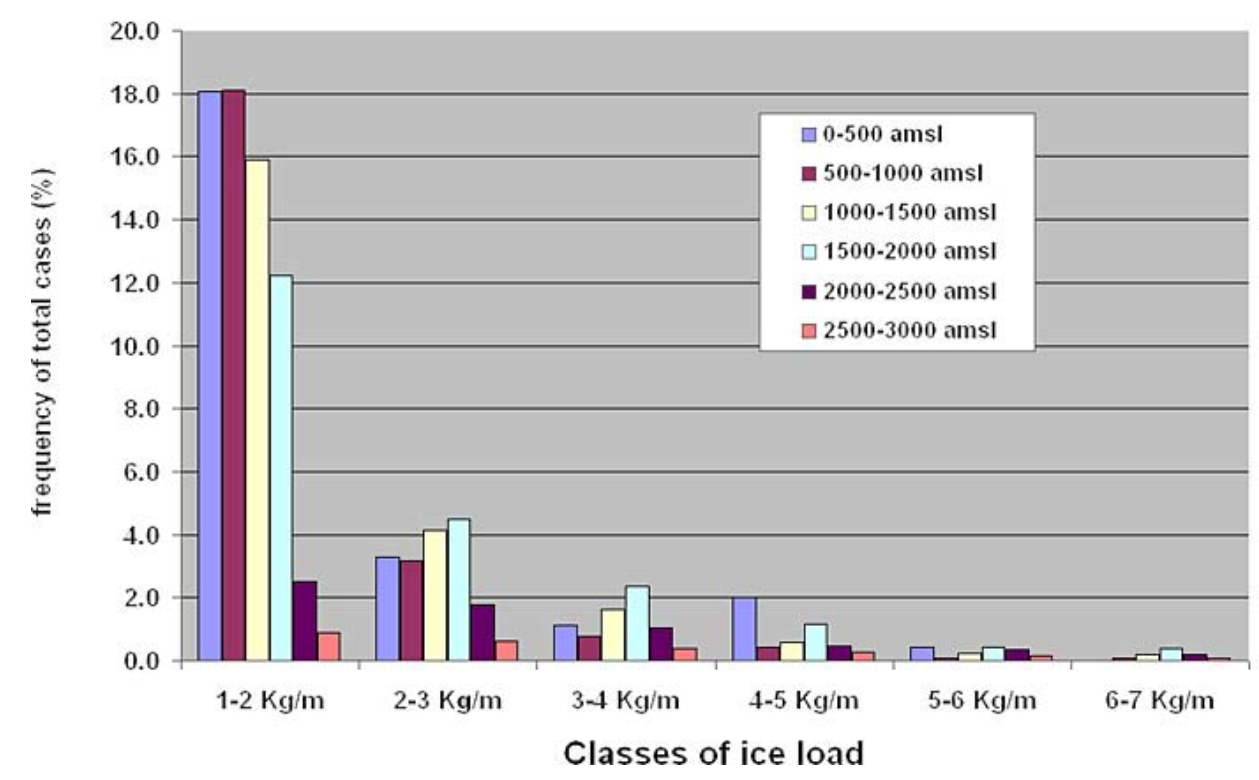

Fig. 13. As in Fig. 12, divided into ranges of altitude and ice load.

temperature variations across the $0^{\circ} \mathrm{C}$. This effect is due to the sudden change of the adhesive characteristics of snow flakes.

\section{Conclusions}

This paper presents a forecast system (WOLF) able to compute ice-accretion on overhead power lines, due to wet-snow. The system provides alarms and displays meteorological and power lines information on an easy GIS interface. WOLF is devoted to the power grid managers that can adopt defence strategies to reduce the effect of possible accidents.

WOLF has been applied in Italy for an entire cold period (November 2009-April 2010), demonstrating the capability to forecast some real accidents and to build datasets, also useful for statistical studies. In that period, WOLF predicted 6 days of severe wet-snow conditions when 2 power line accidents, on different days, occurred in the right areas. A third accident, happened in December 2008, which was correctly predicted by means of a dedicated simulation. These results, demonstrate the WOLF ability to predict critical events and provide alerts, necessary to adopt dispatching strategies, reducing the effects of power supply failures.

Analysing the whole output produced by WOLF, it has been possible to identify the mostly afflicted sites by wetsnow conditions in Italy, although for only one short period. This procedure suggests the possibility to build a climatology of the wet-snow conditions over a wide geographic area.
Experimental campaigns have been carried out in order to measure ice-load and local weather variables involved in the accretion process. Some results have been reported in this paper. The comparison between the WOLF forecasts and the observations, lead to verify the right parameterization of the microphysical processes in the accretion model, expressed by the $\gamma$ factor, but only for a positive temperature close to $0^{\circ} \mathrm{C}$. Sleeve accretion was observed for negative temperature too, but in this case the model does not produce the right forecast and it should be re-tuned.

WOLF has been developed following some hints coming from similar experiences of other countries, but it represents the first effort in Italy on this subject. It is common thinking that a unique general purpose-wide area forecast system could not meet the needs of countries with different climatic conditions and grid management, but it is good practice to develop and test different systems.

The authors realise that the role of wind intensity and its direction on the accretion process has not been investigated, due to the poor experimental data, but they think by improving the knowledge on this topic with further campaigns. Furthermore, the vertical velocity of snowflakes combined with the wind intensity is another important parameter that should be considered, in order to better calculate the effective snow flux on the conductor. The authors experienced that this value cannot be considered constant or negligible.

In the future, the authors plan to improve the WOLF algorithm introducing the heating Joule effect and a more suitable alarm system including SMS messages. 
Acknowledgements. This work has been financed by the Research Fund for the Italian Electrical System under the Contract Agreement between RSE (formerly known as ERSE) and the Ministry of Economic Development - General Directorate for Nuclear Energy, Renewable Energy and Energy Efficiency stipulated on 29 July 2009 in compliance with the Decree of 19 March 2009.

The authors give thanks to their colleague Giovanni Pirovano for providing them with suggestions and some data.

Edited by: N. R. Dalezios

Reviewed by: T. Niedźwiedź and another anonymous referee

\section{References}

Admirat, P. and Sakamoto, Y. : Calibration of a wet-snow model on real cases in Japan and France, in: Proc. 4th International Workshop on Atmospheric Icing of Structures, Paris, 7-13, 1988a.

Admirat, P. and Sakamoto, Y. : Wet snow on overhead lines: a state of the art, in: Proc. of the 4th International Workshop on Atmospheric Icing of Structures, Paris, 7-13, 1988b.

Bonelli, P. and Lacavalla, M. : Experimental activity and investigation of wet-snow accretion on overhead power lines in Italy, in: Proc. 13th International Workshop on Atmospheric Icing of Structures, Andermatt, September 2009.

Bonelli, P. and Lacavalla, M. : Trend in snow deposition on overhead electric lines: using synoptic data to investigate the relationship black-out risk/climate change. Management of Weather and Climate Risk in the Energy Industry, NATO Science for Peace and Security Series - C. Environmental Security, edited by: Troccoli, A., (ISSN: 1874-6519), January 2010.

Bonelli, P., Marcacci, P., and Lacavalla, M.: Caratterizzazione del fenomeno di ghiacciamento di linee elettriche, Rapporto di Ricerca di Sistema WP 3.2, CESI RICERCA, Febbraio 2008.

Cigrè: Guidelines for field measurement of ice loadings on overhead power line conductors, Cigrè Task Force 22.06.01, TB179, 2001.

Cigrè: Guidelines for meteorological icing models, statistical methods and topographical effects, Cigrè Working Group B2.16, TB291, Revision 6, May 2005.

Cigrè: System for prediction and monitoring of ice shedding, antiicing and de-icing for overhead lines. Cigrè Working Group B2.29, September 2009.

Farzaneh, M.: Atmospheric Icing of Power Networks, edited by: Farzaneh, M., Springer Science, 2008.

Fikke, S.: Cost Action 727 Measuring and forecasting atmospheric icing on structures, in: Proc. 11th International Workshop on Atmospheric icing of Structures, Montreal, Canada, June Paper IW64, 2005a.

Fikke, S.: Modern meteorology and atmospheric icing, in: Proc. 11th International Workshop on Atmospheric icing on Structures, Montreal, Canada, June, Paper IW73, 2005b.
Fikke, S., Ronsten, G., Heimo, A., Kunz, S., Ostrozlik, M., Persson, P. E., Sabata, J., Wareing, B., Wichure, B., Chum, J., Laakso, T., Santti, K., and Makkonen, L.: COST 727: Atmospheric Icing on structures, Measurements and data collection on icing: State of the Art, Publication of MeteoSwiss, 75, 110 pp., ISSN:14221381, 2007.

Gland, H. and Admirat, P.: Meteorological conditions for wet snow occurrence in France, Calculated and measured results in a recent case study on March 5th, 1985, in: Proc. of the 3rd International Workshop on Atmospheric icing of Structures, Vancouver, 1986.

IEC: Loading and strength of overhead transmission lines, IEC Technical Report, 1991.

IEC: Overhead lines - Meteorological data for assessing climatic loads, International Electrotechnical Commission Technical Report 61774, 1997.

IEC: Design criteria of overhead transmission lines. International Electrotechnical Commission Technical Report 60826, Ed.3.0, 2003.

Makkonen, L.: Modelling of ice accretion on wires, J. Climate Appl. Meteor., 23, 929-939, 1984.

Makkonen, L.: Estimation of wet-snow accretion on wires, Cold Regions, Sci. Technol., 17, 83-88, 1989.

Makkonen, L.: Models for the growth of rime, glaze, icicles and wet-snow on structures, Phil. Trans. R. Soc. London. A, 358, 2913-2939, 2000.

Olafsson, H., Eliasson, A. J., and Thorsteins, E.: Orographic influence on wet-snow icing, Part 1: Upstream of mountains, in: Proc. 10th International Workshop on Atmospheric Icing of Structures, Brno, Check Republic, June, Paper 2-2, $2002 \mathrm{a}$.

Olafsson, H., Eliasson, A. J., and Thorsteins, E.: Orographic influence on wet-snow icing, Part 2: Downstream of mountains, in: Proc. 10th International Workshop on Atmospheric Icing of Structures, Brno, Check Republic, June, Paper 2-3, 2002 b.

Poots, G.: Ice and snow accretion on wires, Wiley, 1996.

Sakamoto, Y.: Snow accretion on overhead wires. Phil. Trans. R. Soc. London, 358(1776), 2941-2970, 2000.

Thorsteins, E. and Eliasson, A. J.: Iceload measurements in test spans in Iceland - statistical analysis of data, in: Proc. 8th International Workshop on Atmospheric Icing of Structures, Reykjavik, June, 285-289, 1998.

Toth, K., Lakatos, M., Kollath, K., Fulop, R., and Simon, A.: Climatology and forecasting of severe wet snow icing in Hungary, in: Proc. 13th International Workshop on Atmospheric Icing of Structures, Andermatt, September 2009.

Wareing, B. J. and Nygaard, B. E.: WRF Simulation of wet snow and rime icing incidents in the UK, in: Proc. 13th International Workshop on Atmospheric Icing of Structures, Andermatt, September 2009. 